\title{
A ABSTRAC̄̃O EM MOVIMENTO: ABERTURA NOS MÓBILES DE ALEXANDER CALDER E PINTURAS TRANSATLÂNTICAS DE PIET MONDRIAN
} MOVING ABSTRACTION: OPENING IN ALEXANDER CALDER'S MOBILES AND PIET MONDRIAN'S TRANSATLANTIC PAINTINGS

LA ABSTRACCIÓN EN MOVIMIENTO: APERTURA EN LOS MÓVILES DE ALEXANDER CALDER Y LAS PINTURAS TRANSATLÁNTICAS DE PIET MONDRIAN

Débora Visnadi ${ }^{1}$ 


\section{Resumo}

Este artigo evidencia uma relação comparativa entre a obra de dois artistas na vanguarda da produção abstrata: Piet Mondrian na pintura e Alexander Calder na escultura. Nos diversos estudos sobre o desenvolvimento do trabalho de Calder, o papel de Mondrian encontra-se restrito à recepção do artista em seu ateliê em 1930: ao se deparar com os retângulos coloridos, Calder sugeriu movimento a tudo aquilo, culminando em uma série de experimentações abstratas que rapidamente se transformariam em seus conhecidos Móbiles. A divergência teórica entre eles - de um lado a rigidez de Mondrian em seguir as proposições neoplásticas, e de outro a soltura presente em Calder - não são suficientes para anular suas similaridades estilísticas. Assim, este trabalho enfatiza os modos como suas produções se aproximam para além do despertar de Calder à abstração, apoiando-se no conceito de obra aberta de Umberto Eco para evidenciar o modo como seu incomum gênio, ao mesmo tempo apolíneo e dionisíaco, potencializa sua obra.

Palavras-chave: Pintura abstrata; Escultura abstrata; Obra aberta.

\section{Abstract}

The present essay intends to showcase a comparative relation between the work of two artists at the vanguard of abstract production: Piet Mondrian in painting and Alexander Calder in sculpture. In several studies on the development of Calder's work, Mondrian's role is restricted to the reception of the former in his studio, in 1930: when Calder came across the colorful rectangles and the absence of ornamentation, he suggested movement to all of that, which culminated in a series of abstract experiments that would quickly become his known Mobiles. The discrepancy between both of their artistic theories - on one hand Mondrian's inflexibility in following the neoplastic propositions, and on the other Calder's light fluency - are not enough to cancel the stylistic similarities of their artwork. Therefore, this research emphasizes how their kinship goes beyond Calder's awakening to non-figurative art, while it relies on Umberto Eco's open work concept to showcase how their unusual genius, both Apollonian and Dionysian, potentiates their artwork.

Key-words: Abstract painting; Abstract sculpture; Open work.

\footnotetext{
1 Mestranda em Artes Visuais pela Universidade Estadual de Campinas, na linha de pesquisa de Fundamentos Teóricos. Possui experiência em pesquisa de arte abstrata, arte moderna e arte moderna brasileira. Lattes: http://lattes.cnpq.br/4944637124581011

Orcid: https://orcid.org/0000-0002-9979-5303

debora.visnadi@gmail.com
} 


\section{Resumen}

Este artículo destaca una relación comparativa entre el trabajo de dos artistas en la vanguardia de la producción abstracta: Piet Mondrian en pintura y Alexander Calder en escultura. En varios estudios acerca del trabajo de Calder, el papel de Mondrian se limita a la recepción del primero en su estudio, en 1930: cuando Calder encontró los coloridos rectángulos y la ausencia de ornamentación, sugirió la introducción del movimiento, lo que culminó en una serie de experimentos abstractos que rapidamente se convertirían en sus conocidos Móviles. La discrepancia entre sus dos teorías artísticas, por un lado la rigidez de Mondrian al seguir las proposiciones neoplásicas, y por otro, la soltura presente en Calder, no es suficiente para anular sus similitudes estilísticas. Por lo tanto, esta investigación enfatiza cómo sus producciones se acercan más allá del despertar de Calder a la abstracción, confiando en el concepto de obra abierta de Umberto Eco para mostrar cómo su genio inusual, tanto apolíneo como dionisíaco, potencia su obra de arte.

Palabra-clave: Pintura abstracta; Escultura abstracta; Trabajo abierto.

ISSN: 2175-2346 


\section{Introdução}

Ainda que não tenha sido o primeiro a introduzir o movimento de fato como parte integrante de uma obra artística, o norte-americano Alexander Calder (18981976) permitiu o estabelecimento da forma dinâmica como parte da linguagem escultórica: sua extensiva dedicação em investigar relações de cor e forma em um movimento real the rendeu o título informal de "pai da arte cinética". Desse modo, ainda que tenha começado a desenvolver seus Móbiles em 1930, cerca de uma década após as primeiras investigações abstratas na escultura ${ }^{1}$, a nova forma de pensamento proposta configurava uma obra essencialmente não figurativa, permitindo-lhe compor o quadro de pioneiros da abstração na produção tridimensional. O pintor holandês Piet Mondrian (1872-1944) teve papel central para que Calder introduzisse novas definições de cor e forma a seu trabalho; ainda que por meio apenas de uma dupla de encontros, a impressão deixada pelo contato se deu em tão alto grau que modificou significativamente o trabalho do americano.

Os artistas produziram obras muito próprias e características, cuja autoria não causa confusão. Ainda assim, seus elementos compositivos, como o uso das cores puras e as formas geométricas ou beirando a geometria, aproximam-se. A questão rítmica é o que se altera, sendo possível traçar paralelos entre a variação desse elemento e o conceito de obra aberta proposto por Umberto Eco: quanto mais vemos uma abertura da obra a diversas possibilidades de apresentação, mais presente se torna a questão rítmica.

Por possuir sua produção centrada no meio bidimensional, a questão rítmica no trabalho de Mondrian se apresenta enquanto sugestão ao olhar. Desse modo, sua obra não possui capacidade de reconfiguração, não podendo ser inserida no conceito de obra aberta - no entanto, veremos que diversas propriedades presentes em sua extensiva exploração neoplástica formarão caminho para essa abertura.

Já na obra de Calder, cada um de seus trabalhos possui diferentes apresentações, dependendo tanto do acaso como da colocação do espectador em frente à obra. O ritmo, dessa forma, além de ser trazido pela organização compositiva, é também parte de uma abertura.

\section{Desdobramentos abstratos de Mondrian e Calder}

À época do mencionado encontro, os dois artistas haviam deixado seus países de origem para morarem e trabalharem na França, em sua efervescente capital, centro de distintos pensamentos e manifestações de vanguarda. Até então, Calder desenvolvia um trabalho de natureza lúdica, seu circo de marionetes, cujas apresentações tornaram-se cada vez mais conhecidas a partir de 1927 - o espetáculo de variedades contava com uma série de mecanismos que colocava em movimento as figuras confeccionadas em arame, madeira e outros materiais. Alguns de seus acrobatas eram feitos apenas em metal retorcido; as formas vazadas faziam com que os

10 Manifesto Realista dos irmãos Naum Gabo (1890-1977) e Antoine Pevsner (1884-1962), por exemplo, data de 1920 e já traz ideias quanto ao movimento real enquanto um elemento escultórico, em oposição ao ritmo meramente sugerido, com suas obras caminhando ao lado daqueles ideais. 
trabalhos, apesar de tridimensionais, apresentassem-se enquanto contorno, não permitindo uma percepção muito profunda de peso e volume. Não fosse a combinação entre os artistas de brinquedo, equilibrando-se em um balanço calculado, poderiam se apresentar como desenhos no espaço. Calder utilizou esta técnica para compor peças únicas que não integravam o Cirque e que foram expostas em algumas mostras em galerias, não deixando, contudo, aquele humor espirituoso de lado.

Desse modo, percebe-se que, até então, apesar de duas gerações de artistas o precederem na família, Calder não se inquietava com as questões da arte que se apresentavam naquele momento, nem se inseria nas discussões do desenvolvimento vanguardístico. Sua amizade era com artistas de menor reconhecimento, e a formação na área da engenharia permitia a criação dos recursos para dar vida à sua trupe simulada, realizando as apresentações do circo mais como um modo de divertir seus espectadores.

O primeiro artista moderno de maior alcance com que veio a ter contato foi Joan Miró (1893-1983), em 1928, através da sugestão de um amigo em comum. Trocaram visitas em seus estúdios, mas Calder não pôde entender ou se relacionar ao seu trabalho então. Foi somente após a criação abstrata dos Móbiles que eles voltaram a se relacionar, estabelecendo uma amizade e admiração profissional mútua que duraria até o fim de suas vidas. Além de Miró, outros artistas foram levados aos espetáculos do Cirque Calder devido à propaganda de seus admiradores. Foi então que Fernand Léger (1881-1955), Theo van Doesburg (1883-1931) e Piet Mondrian compareceram a uma dessas apresentações - o entusiasmo demonstrado pelo último é o que leva o norte-americano à visita em seu ateliê, sendo neste encontro que as coisas começam a mudar no programa artístico de Calder:

Fiquei muito movido pelo ateliê de Mondrian, amplo, belo e irregular em suas formas, com as paredes pintadas de branco e divididas por linhas pretas e retângulos de cores fortes, como em suas pinturas. Era muito encantador, com luzes entrecruzadas (havia janelas dos dois lados), e eu pensei no momento como seria bom se tudo ali se movesse; embora o próprio Mondrian não aprovasse a ideia. Fui para casa e tentei pintar. Mas o arame - ou algo para torcer, romper ou dobrar - é um meio em que posso pensar mais facilmente. Comecei com algumas formas simples. (CALDER, 1937, p. 63, tradução nossa)

Antes de chegar aos primeiros Móbiles, Calder fez experimentos com a pintura por algumas semanas; despertado pelo encontro com Mondrian, a cor passou a fazer parte de sua composição para nunca mais se dissociar das formas. Ainda que o artista aponte outros companheiros como preponderantes para a evolução de seu percurso, como aqueles já citados, o contraste entre os volumes coloridos - de tons fortes e 
chapados - e o preto dos fios de metal (figura 1) demonstra o quanto aquele encontro foi o ponto de inflexão para que passasse a pensar de fato a arte e a abstração.

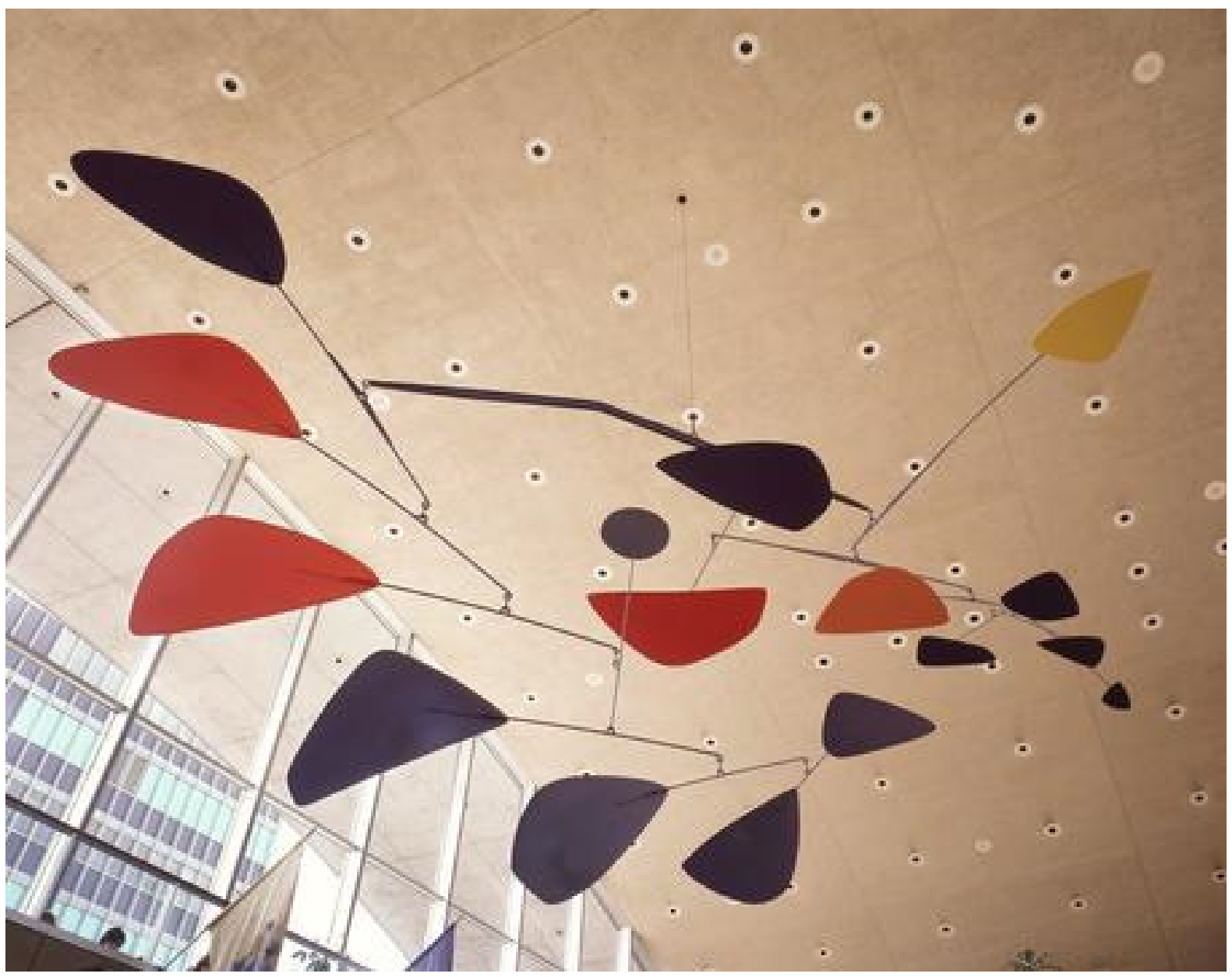

Figura 1 - Alexander Calder: 125, 1957. Chapa metálica, haste e tinta. 7,5 x 13,5 x 5m. (fonte: <www.calder.org>)

A produção artística de Mondrian pela qual é mais expressivamente conhecido conta com a utilização das cores primárias puras e das linhas ortogonais (figura 2). Os componentes básicos na composição da tela configuravam o que acreditava ser a eliminação de impressões individuais - buscando a pureza, a manifestação da personalidade do artista entraria em conflito com os princípios universais que Mondrian acreditava regerem o todo da arte e da vida. Desse modo, a abstração representaria para ele um modo mais direto de atingir esses fins, uma vez que a figuração apresentava suas relações puras "'veladas' na pintura mais antiga pelos traços da natureza, que apenas distraíam o observador do universal e absoluto na arte" (SCHAPIRO, 2001, p. 30-31):

O espírito, ao triunfar, não pode mais se apresentar sob a mimese de formas naturais, devendo reduzi-las a si, abstraí-las e depurá-las, até chegar à verdade e à beleza que lhe são próprias e melhor manifestas por retas, planos retangulares e cores primárias. Sendo universal, esse espírito recusa tanto a arte que se origina das aparências externas quanto a que é pensada como expressão da individualidade e da subjetividade. (BRANDÃO, 2008, p. 12) 


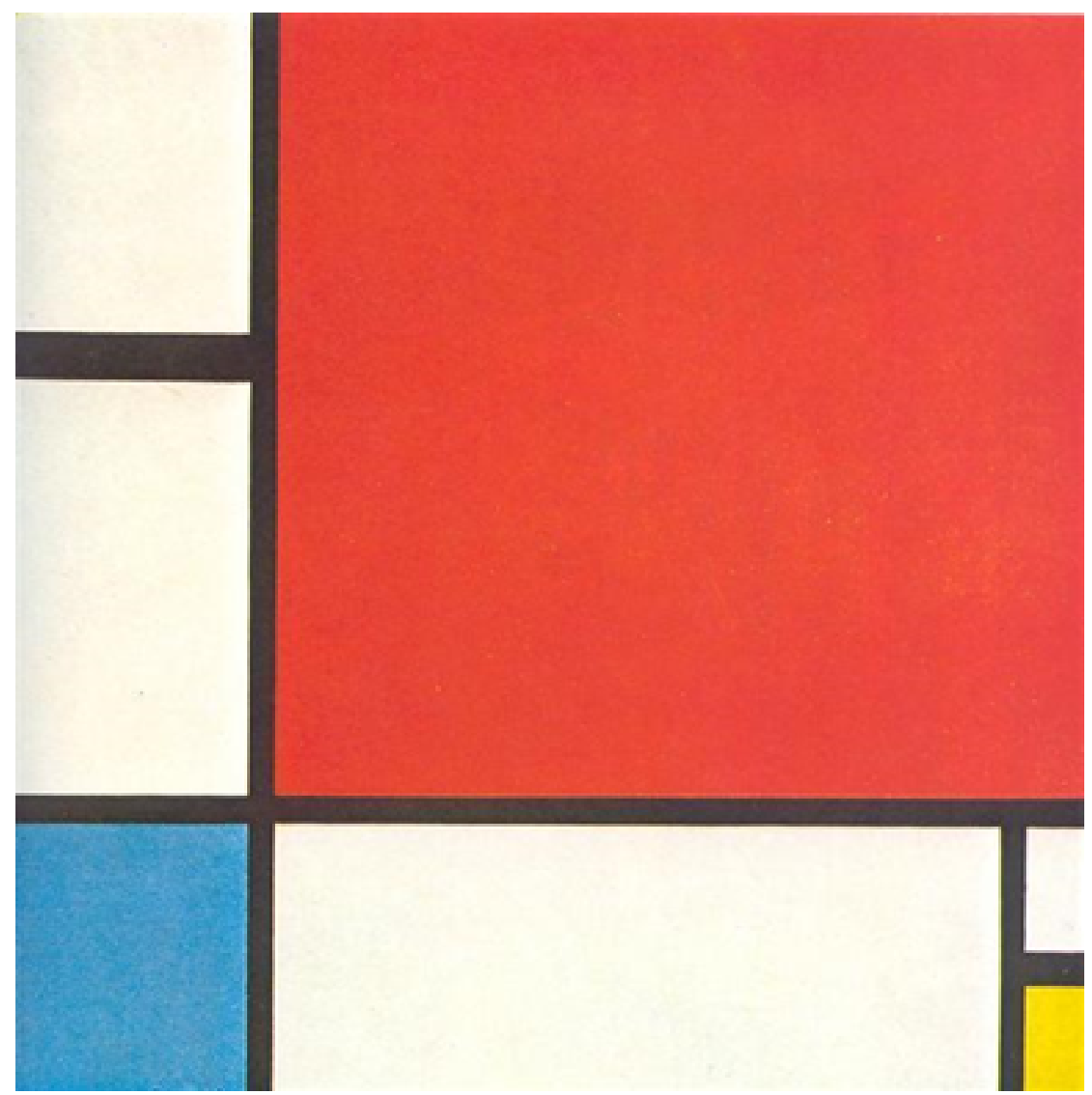

Figura 2 - Piet Mondrian: Composição em vermelho, azul e amarelo, 1930. Óleo sobre tela. 66x86cm. (fonte: <www.wikiart.org>)

Desse modo, é visando à síntese entre natureza e espírito que Mondrian chega ao uso do vermelho, amarelo e azul em sua obra, uma vez que tais cores surgem "depois de depurarmos e reduzirmos as que percebemos na natureza" (MONDRIAN, 2008, p. 15).

Sua composição é também guiada pelo princípio do equilíbrio assimétrico: uma vez que se deve dotar de tensão interna, o uso da repetição par a tornaria estática. É a partir desse sentido que a dinamicidade integra fundamentalmente seu trabalho, justificando a negativa à sugestão de Calder de transferir um movimento real a sua pintura. "Não, não é necessário, minha pintura já é bem rápida" (MONDRIAN apud CARANDENTE, 1968, p. 14, tradução nossa) é a resposta de Mondrian, que evidencia justamente o ponto levantado. E de fato, seus trabalhos são dotados de ritmo, ainda que seja sempre virtual, interno à concepção da tela, e diferente da questão cinética que Calder viria a explorar. No entanto, a rigidez do artista em seguir os mencionados princípios neoplásticos à risca, uma vez que se integram a sua visão de mundo, é motivo pelo qual esse movimento encontra-se ainda muito inflexível.

Pode-se exemplificar o desejo de Mondrian de manter-se fiel à universalidade que buscava através do episódio em que rompe com o grupo De Stijl e, especialmente, com Theo van Doesburg: seu companheiro utiliza uma diagonal naquele sistema de ângulos retos que haviam teorizado, o que, para Mondrian, implicou em uma "correção arbitrária" (SCHAPIRO apud CARANDENTE, 1968, p. 27), de caráter pessoal, que invalidava qualquer tipo de colaboração posterior. Apesar de tal dogmatismo - ou 
talvez justamente por ele - seu trabalho não é esvaziado de humanidade: intelectual, sim, mas também sensível e espiritual, Mondrian segue regras por acreditar em uma visão teosófica de que "o mundo compreende matéria, intelecto ou consciência, e espírito ou divindade, todos interligados numa fusão dinâmica evolutiva" (MILNER, 1992, p. 10, tradução nossa). Busca, portanto, uma combinatória entre elementos aparentemente opostos a um primeiro olhar desatento, buscando uma forma de elevação espiritual em seu exercício de pintor, o que resolve conflitos internos que uma vez tivera, relativos à escolha da arte ou da religião.

Calder, ao contrário do holandês, que deixou inúmeros escritos detalhando suas teorias e as premissas da associação de vanguarda que integrava, aqui apresentadas, afirma querer discutir apenas aquilo que já produziu. Para ele, "teorias podem funcionar muito bem para o artista, mas não devem ser transmitidas a outras pessoas" (CALDER, 1937) uma vez que temia se sentir obrigado a fazer seu trabalho subsequente se encaixar na explicação. Ainda que tivessem essa visão praticamente oposta sobre o papel da teoria no desenvolvimento do trabalho artístico, essa divergência se tratava, na verdade, de quanto conhecimento o público teria sobre seu princípio guiador. Calder, como Mondrian, também aponta a simetria como algo indesejável em seus trabalhos, sendo que para ele "a coisa mais importante na composição é a disparidade" (CALDER, 1943); e vê, similarmente, no universo uma das maiores fontes de estímulo para seu trabalho, ainda que não do mesmo modo teosófico de Mondrian, mas através das formas, das constelações. Assim, não seria o modo como abordam a teoria na arte - nem a rigidez com que a seguiriam - que colocaria em xeque sua possível similaridade artística.

A aproximação maior entre suas obras se dá justamente quando Mondrian se muda para os Estados Unidos - terra natal de Calder e onde ele voltara a residir - na década de 1940, onde passaria os últimos anos de sua vida. Levando um conjunto de obras não finalizadas que iniciara na Europa - conhecidas como pinturas transatlânticas (figuras 3 e 4) - é nesta época que permite que os princípios neoplásticos não atuem de maneira tão rígida na concepção de sua pintura: profundo admirador do jazz e do teatro musical, é ao ter um contato mais direto com estas manifestações artísticas que as questões do movimento adquirem maior liberdade. As linhas pretas aparecem em maior número e se tornam por vezes mais curtas ou mais longas, sobrepondo-se aos retângulos coloridos; os tons de amarelo, vermelho e azul não sofrem variações, mas passam a fazer parte do conjunto de traços verticais e horizontais. Tudo isso gera uma sensação de ritmo ainda mais aprofundada do que o que fora sugerido até então. 


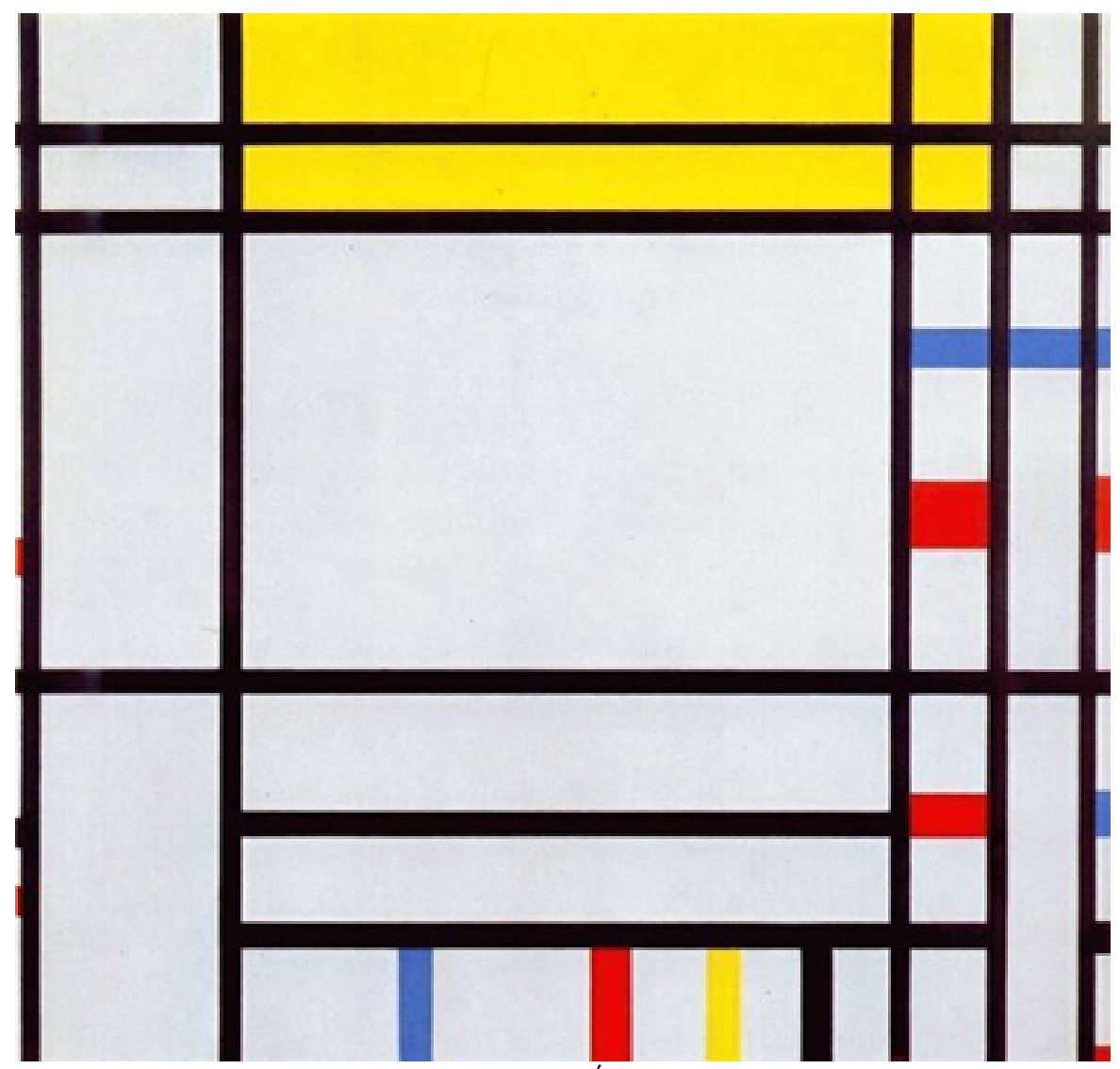

Figura 3 - Piet Mondrian: Place de la Concorde, 1938-1943. Óleo sobre tela. 94 x 95 cm. (fonte: <www.wikiart.org>)

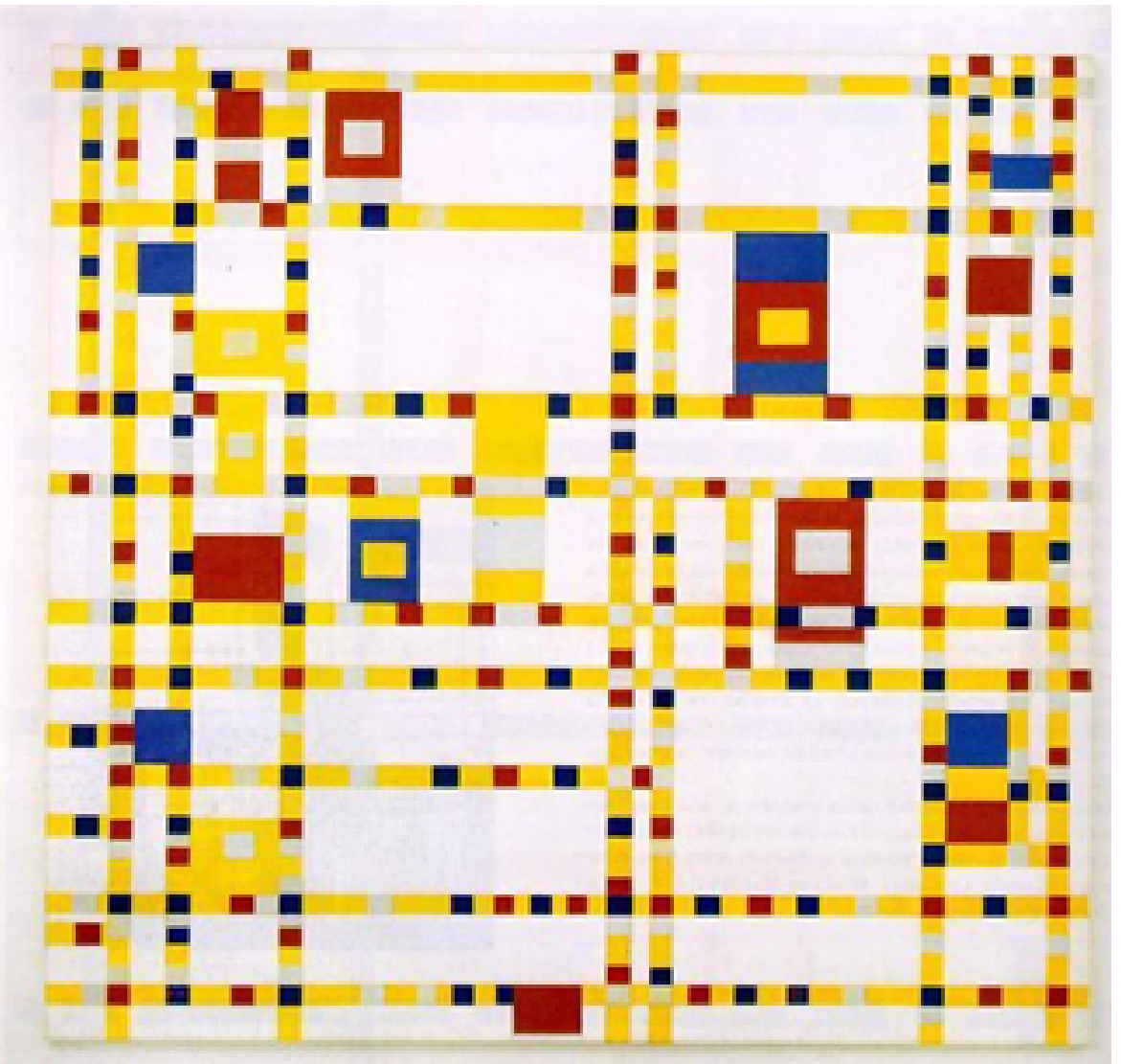

Figura 4 - Piet Mondrian: Broadway Boogie-Woogie, 1942-1943. Óleo sobre tela. 127 x 127 cm. (fonte: <www.wikiart.org>) 
Uma das questões apontadas pelo neoplasticismo seria a da harmonização entre arte e vida, por se ligarem às leis universais, chegando Mondrian a acreditar que "no futuro [...] já não precisaremos de quadros, pois viveremos o meio da arte realizada" (MONDRIAN apud CHIPP, 1996, p. 320). Nesse momento, ao contrário, o pintor deixa que a "vida" permeie sua composição artística, como aponta o curador Harry Cooper, em livro sobre estas pinturas de Mondrian:

O momento "ainda não era maduro" (como ele dizia) para a dissolução da arte na vida cotidiana. Na verdade, era o oposto: ele estava de alguma forma trazendo a vida de Manhattan à sua arte, onde poderia causar um caos cuidadosamente controlado. [...] Mais do que se assimilar ao novo ambiente, ele tentou assimilá-lo a si mesmo. (COOPER, 2001, p. 46-47, tradução nossa)

Assim, é com uma nova visão dos princípios que regeram a maior parte de seu trabalho que a obra de Mondrian se vê mais próxima da de Calder. O norte-americano chegou ao ponto da integração entre arte e ambiente urbano da vida cotidiana: por meio dos seus trabalhos monumentais, nos quais chega a combinar, em certos momentos, estruturas móveis e estáticas (figura 5). No entanto, devido à questão rítmica, aponta-se aqui uma aproximação entre os Móbiles de Calder e as pinturas transatlânticas de Mondrian, que encontram maior soltura em seu desenvolvimento. Normalmente, o trabalho de Calder é altamente relacionado ao do pintor Joan Miró nas questões de afinidade artística; não convém aqui argumentar que sua maior aproximação seria a Mondrian, mas evidenciar outras correspondências em seu trabalho, demonstrando como sua relação vai além do despertar de Calder à escultura abstrata em 1930.

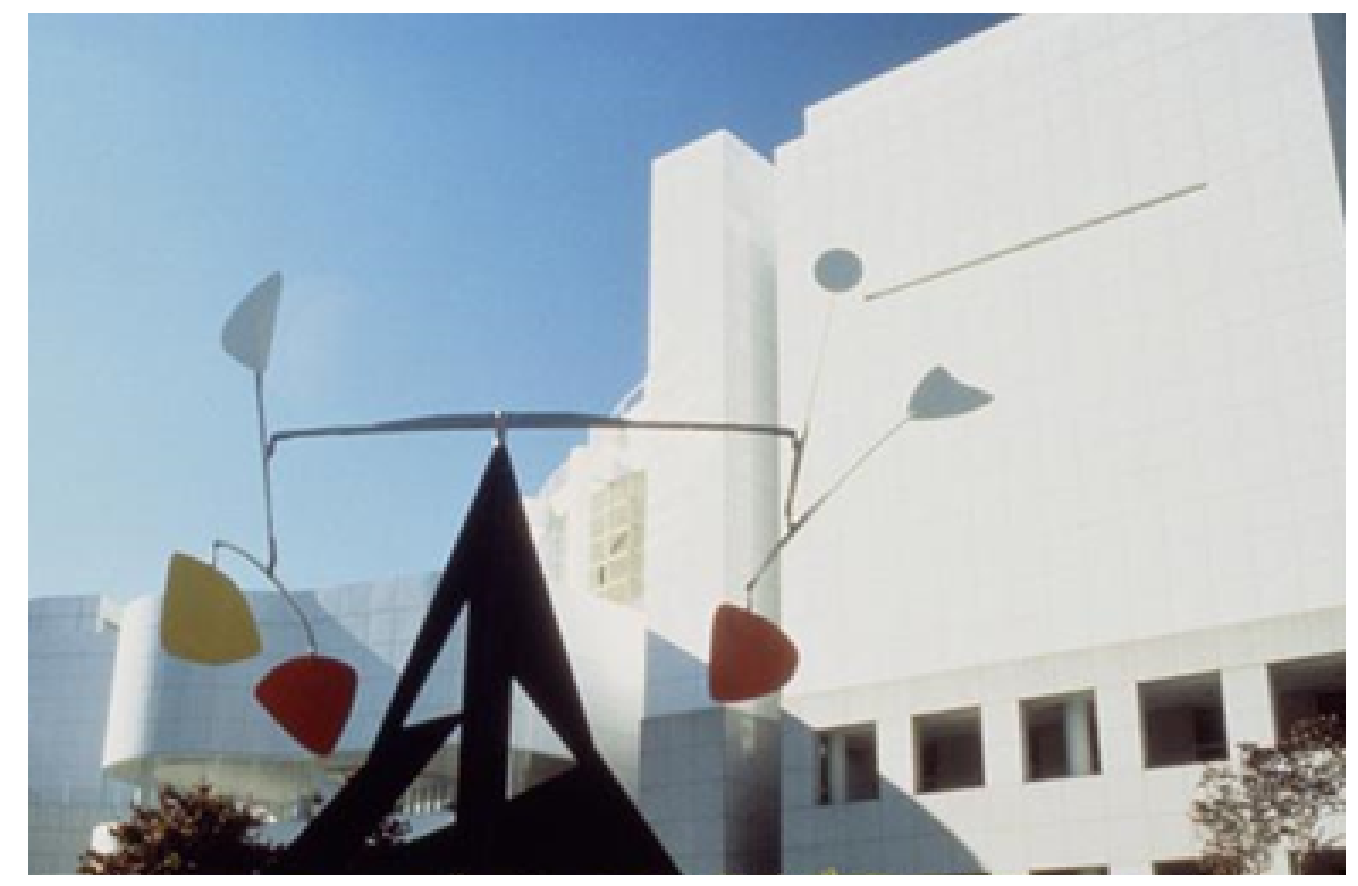

Figura 5 - Alexander Calder: Cinco vazios ou Três para cima, três para baixo, 1973. Folha metálica, haste, parafuso e tinta. 7 x 6,5 x 6,5m. (fonte: <www.calder.org >) 


\section{Ritmo sugerido e ritmo dinâmico}

Mondrian, a todo momento, estabelece relações com outras artes - notadamente a arquitetura, como mencionado - , inclusive com seu grupo de atuação artística contando com representantes da área. Não é por acaso que apresenta tais vínculos: a integração entre arte e vida almejada não poderia encontrar meio mais fecundo para se afirmar do que o das construções, que exercem esse papel por definição. Calder cerca-se, também, de arquitetos, principalmente em viagens ao Brasil, onde, através de Mário Pedrosa, estabelece amizade com Henrique Mindlin, Lina Bo Bardi, Flávio de Carvalho, entre outros - o que também não é coincidência: ao propor o movimento real na escultura, o norte-americano traz a obra ao espectador, atribuindo a ela um caráter de proximidade análogo ao da arquitetura e sendo catalisador de uma relação orgânica ambiental:

Finalmente, a obra de Calder oferece extraordinárias possibilidades para a integração da escultura na arquitetura nova de nossos dias. Basta imaginar um de seus grandes móbiles suspenso no pórtico de um dos nossos edifícios novos, por exemplo no Ministério da Educação ou no Instituto de Resseguros, basta visualizá-lo tocado pela brisa, enchendo o espaço claro com os seus ritmos sempre novos, para compreender não só a importância das contribuições que Calder traz à nova arquitetura, como especialmente daquela que poderia trazer para a arquitetura do sol e dos espaços abertos que se realiza no Brasil (MINDLIN ,2006, p. 58)

Própria da música, a dimensão temporal inaugurada nos Móbiles é um dos fatores que configura na proposta de Calder aquilo que Umberto Eco chama de obra aberta, sendo indissociável da questão espacial apontada que aproxima a escultura do espectador, suspendendo e tirando-a de um apoio expositivo típico dessa linguagem. Visando indicar como são propostos certos problemas artísticos, uma obra aberta traz "uma mensagem fundamentalmente ambígua, uma pluralidade de significados em um só significante" dependendo "da intervenção ativa do consumidor, sem, contudo, deixar de ser 'obra'" (ECO, 1976, p. 22-23). Desse modo, o caráter cinético presente nesses trabalhos de Calder faz com que sua estrutura se reorganize a cada momento, completando-se em frente do espectador, ou como Umberto Eco coloca, trazendo em si "uma capacidade de reproduzir-se caleidoscopicamente aos olhos do fruidor como eternamente novos" (ECO, 1976, p. 51).

Essa questão é abordada por Mário Pedrosa em texto de 1948, em que disserta a respeito da tensão presente no repouso de um Móbile: funcionando como uma espécie de energia potencial, a espera pelo movimento traz na obra todas suas variações possíveis apenas esperando para aflorar:

O movimento neles não visa à impressão de um instante; visa, ao contrário ao que há de mais eterno, perene, imutável no conceito do dinâmico, isto é, sua perpétua e ilimitada virtualidade, e que se manifesta paradoxalmente sobretudo no repouso. O repouso contém potencialmente todas as formas ideais, desencarnadas de qualquer convenção ou representação. Se a forma 
é a fonte irredutível de toda ideia cinética, o movimento é o princípio latente da forma; é a origem geradora de toda forma. Os objetos calderianos são construídos para permitir todas as variações possíveis da forma. (PEDROSA, 2006, p. 132)

Desse modo, percebe-se que a abertura em um Móbile de Calder está presente mais em sua potência em assumir diversas identidades do que em seu movimento propriamente dito. Esse tipo de abertura se encaixa no que Julio Plaza classifica posteriormente como de "primeiro grau" (PLAZA, 2003, v. 1, p. 9), sendo os níveis subsequentes mais ligados à participação efetiva do espectador em uma obra de arte, recompondo-a de modo direto. Dessa maneira, o vazio aponta na direção de uma obra aberta, não sendo, contudo, algo a ser preenchido - é como o repouso em Calder, "manancial prenhe de potência de onde, pela dança da energia, nascem todas as formas" (PLAZA, 2003, v. 1, p. 13). Dentre uma breve lista de artistas que Plaza (2003, v. 1) aponta possuírem essa característica, Mondrian figura no topo, uma vez que os retângulos brancos presentes em suas telas neoplásticas funcionam como um hiato e não como um vazio destituído de sentido.

E são essas lacunas que levam Ferreira Gullar a chamar os Móbiles de "escultura às avessas" (GULLAR, 2006, p. 226): ao contrário do que tradicionalmente se entendia como escultura, uma peça apresentando massa e volume fechados, Calder se utiliza de elementos típicos do desenho para compor seus trabalhos, uma vez que os arames e placas de metal colorido transparecem uma relação de linha e plano. Desse modo, trabalhando essencialmente no meio tridimensional, Calder reconfigura essa linguagem, inserindo-se em seu desdobramento moderno: antes das experimentações cubistas (decomposição) e futuristas (velocidade), a escultura fazia uso de outras estratégias para apresentar o objeto como um todo, como a sua representação através de múltiplos pontos de vista. O movimento efetivado propõe uma solução para essas alternativas e integra arte e indivíduo, funcionando como estratégia para solucionar um desejo antigo da arte: tornar palpável aquilo que até então poderia apenas ser representado.

Tudo isso faz parte da disposição dos Móbiles enquanto estruturas abertas, apresentando um vazio cheio de potencialidade e uma movimentação, semelhante à obra de Mondrian, ainda que o último componente seja, em seu caso, sugerido. O pintor também se insere em outra questão "fundamentalmente ambígua", uma estrutura na arte que Rosalind Krauss introduz como grade, referindo-se a formas exclusivamente modernas de caráter geométrico, que trazem intersecções de planos e evidenciam a bidimensionalidade da pintura:

Há duas maneiras pelas quais a grade funciona para declarar a modernidade da arte moderna. Um é espacial; o outro é temporal. No sentido espacial, a grade afirma a autonomia do domínio da arte. Achatada, geométrica, ordenada, é antinatural, antimimética, antireal. É o que a arte parece quando virar as costas para a natureza. [...]

Na dimensão temporal, a grade é um emblema da modernidade por ser exatamente isso: a forma que é onipresente na arte do nosso século, enquanto não aparece em nenhum lado, na arte do último. (KRAUSS, 1999, p. 9-10) 
A estrutura é contraditória, segundo Krauss (1999), por se encontrar fundamentada ao mesmo tempo pela originalidade e pela repetição. Mondrian e o pintor russo suprematista Kazimir Malevich (1878-1935), além de explorarem as formas de arte relativas à grade, foram os que mais teorizaram a seu respeito, deixando como legado inúmeros escritos e publicações - ambos possuíam uma motivação espiritual, ainda que com dadas particularidades, buscando o Universal através da redução das formas da arte aos elementos mais simples e puros.

Já foi mencionado que Mondrian insere questões da ordem da intuição e do intelecto, da matéria e do espírito, em seu programa artístico. E, não só isso, ele se vale de todas essas dualidades para alavancar sua obra em direção a uma evolução, visando um equilíbrio dinâmico dotado de questões rítmicas:

O belo é o verdadeiro contemplável. E o verdadeiro é a multiplicidade de opostos; se quisermos achar o verdadeiro no belo, então é preciso descobri-lo como multiplicidade de opostos. Encontramos o belo em si como multiplicidade do que é linguística ou matematicamente exprimível nas relações quantitativas. (BOLLAND apud MONDRIAN, 2008, p. 76)

O que se aponta aqui é que a pluralidade de significados não se configura como um paradoxo, como aponta Krauss (1999), mas como uma abertura - oposições em harmonia, que não se anulam mas se potencializam. Percebe-se uma coexistência do gênio apolíneo e dionisíaco: Calder utilizando a sistemática engenharia para revelar o lúdico e Mondrian fazendo uso de ligações espirituais para se manifestar com precisão matemática. E esta confluência é algo que aparece com mais frequência no século $X X$ do que em qualquer outro, tornando-se comum à medida que a obra de arte se abre cada vez mais à participação do espectador.

Isso se demonstra por artistas que tiveram inspiração tanto em Calder como em Mondrian, sendo o brasileiro Hélio Oiticica (1937-1980) o exemplo mais claro dessa questão. Principal expoente do Neoconcretismo, tinha sua produção ligada ao conceito de não-objeto levantado por Ferreira Gullar em 1959, formulação que anda de braços dados à noção de obra aberta, como uma abertura de segundo grau. Sendo "um objeto especial em que se pretende realizar a síntese de experiências sensoriais e mentais" (GULLAR, 1999, p. 289), é no não-objeto que o espectador deixa a contemplação para fazer parte da obra. Os artistas do grupo propunham uma revisão crítica da racionalização dos movimentos concretistas a que se associavam, passando a buscar aspectos da sensorialidade na arte enquanto ainda ligados à geometrização. Assim, evidencia-se o caráter apolíneo e dionisíaco em que se desdobra a abertura iniciada por Calder, na movimentação efetiva, e por Mondrian, na ambiguidade da grade.

Essas noções só poderiam se manifestar em uma arte essencialmente abstrata, organizada por soluções a um interesse de igual intensidade entre o palpável e o imaterial. Estabelece-se aqui a confluência desses gênios - de um lado, a ordem e harmonia, e de outro, a expressão e o instinto - como uma característica da obra aberta, que pensa minuciosamente a estrutura que compõe, mas permite aos sentidos uma resolução final. Calder e Mondrian são dotados de uma capacidade de síntese entre 
questões da intuição e do intelecto no universo da arte, denotando como seus cruzamentos vão além do encontro em 1930, o que é evidenciado tanto pelas questões plásticas que se põem frente ao espectador, como pelas perspectivas teóricas que se encontram por trás das obras e que continuamente instigam artistas de gerações posteriores.

\section{Referências}

BRANDÃO, C. L. A Arte contra a natureza: filosofia, pintura e arquitetura em Mondrian. In: MONDRIAN, P. Neoplasticismo na pintura e na arquitetura. São Paulo: Cosac Naify, 2006, p. 7-23.

CALDER, A. À Propos of Measuring a Mobile. 1943. Disponível em: <http://calder.org/ system/downloads/1943_A_Propos.P2903.pdf>. Acesso em: 30 mar. 2017.

Mobiles. In: EVANS, M. (ed.). The Painter's Object. London: Gerold Howe, 1937, p. 62-67. Disponível em: <http://www.calder.org/life/system/downloads/1937_Mobiles.P0301.pdf>. Acesso em: 30 mar. 2017.

CARANDENTE, G. Calder: mobiles and stabiles. New York: New American Library, 1968.

CHIPP, H. B. Teorias da arte moderna. São Paulo: Martins Fontes, 1996.

COOPER, H. Mondrian: The transatlantic paintings. New Haven: Yale University Press, 2001.

ECO, U. Obra aberta: forma e indeterminação nas poéticas contemporâneas. São Paulo: Perspectiva, 1976.

GULLAR, F. Etapas da arte contemporânea: do cubismo à arte neoconcreta. Rio de Janeiro: Editora Revan, 1999.

GULLAR, F. Calder e a alquimia do peso. In: SARAIVA, R. (org.). Calder no Brasil: crônica de uma amizade. São Paulo: Cosac Naify, 2006, p. 225-228.

KRAUSS, R. The originality of the avant-garde and other modernist myths. London: MIT, 1999.

MILNER, J. Mondrian. New York: Abbeville, 1992.

MINDLIN, H. Alexander Calder. In: SARAIVA, R. (org.). Calder no Brasil: crônica de uma amizade. São Paulo: Cosac Naify, 2006, p. 54-58. 
MONDRIAN, P. Neoplasticismo na pintura e na arquitetura. São Paulo: Cosac Naify, 2008. PEDROSA, M. Tensão e coesão na obra de Calder. In: SARAIVA, R. (org.). Calder no Brasil: crônica de uma amizade. São Paulo: Cosac Naify, 2006, p. 124-135.

PLAZA, J.Arte e interatividade: autor-obra-recepção. ARS (São Paulo), São Paulo, v.1, n.2, dez. 2003. Disponível em: <http://dx.doi.org/10.1590/S1678-53202003000200002>. Acesso em: 25 nov. 2017.

SCHAPIRO, M. Mondrian: A dimensão humana na pintura abstrata. .São Paulo: Cosac Naify, 2001. 